\title{
LA GRAMÁTICA DEL SABER ESCOLAR
}

\author{
THE SCHOOL'S KNOWLEDGE GRAMMAR
}

\section{A GRAMÁTICA DO SABER ESCOLAR}

Alejandro Alvarez Gallego ${ }^{1}$

\section{RESUMEN}

El artículo da cuenta del trabajo de investigación que el autor realizó durante su año sabático (septiembre 2018septiembre 2019). Se recogen aquí los antecedentes investigativos que llevaron al autor a plantearse una pregunta por la vigencia de la escuela y la necesidad de unas herramientas que permitan pensar su actualidad. Se mencionan los principales referentes teóricos que se tuvieron en cuenta para construir la categoría de Gramática del Saber Escolar: los estudios etnográficos, la nueva historia cultural, los estudios sobre cultura escolar, sobre el saber escolar y el saber pedagógico. Finalmente se expone lo que se entiende por gramática y las reglas que se encontraron como claves para pensar el saber que se produce en la escuela contemporánea. Se explica cada una de ellas: el tiempo vivo, los afectos abiertos, las funciones intersectadas y el excedente como posibilidad. Estos aportes también recogen la experiencia que el autor tuvo como director de un colegio durante cuatro años y de cuya sistematización surgieron las reglas que se proponen para dar lugar a la categoría de Gramática del Saber Escolar.

PALABRAS CLAVE: Gramática del saber escolar. Escuela. Saber escolar. Cultura escolar.

\begin{abstract}
The paper describes the author's research project completed during his sabbatical year from September 2018 to September 2019. It covers the research background that inspired the author to question validity of the school and the need to come up with new tools that allow us to reimagine its contemporary relevance. It touches on the main theoretical referents that were considered to construct the School's Knowledge Grammar: ethnographic studies, the new cultural history, and studies discussing scholar culture, scholar knowledge and pedagogical knowledge. Lastly, it explains what is understood by "Grammar" and the key principles that are used to explain the knowledge produced in today's contemporary school. Each of these key principles are explained, including: Kinetic time, Open emotions, Intercepted roles, and Excess as a possibility. These conclusions also include the experience the author had as Director of a school for four years and the systemization that gave birth to the principles that are proposed to categorize the School Knowledge Grammar.
\end{abstract}

KEYWORDS: School knowledge grammar. School. School knowledge. School culture.

\footnotetext{
${ }^{1}$ Doctor en Historia de la Educación y Educación Comparada - Universidad Nacional de Educación a DistanciaUNED - Madrid, España. Profesor Titular de la Facultad de Educación - Universidad Pedagógica Nacional. Bogota Colombia. Miembro Fundador "Grupo de Investigación Historia de la Práctica Pedagógica-GHPP en Colombia” - Colômbia. E-mail: aalvarez@pedagogica.edu.co

Submetido em: 22/06/2020 - Aceito em: 04/09/2020
}

(C) ETD- Educação Temática Digital
Campinas, SP v. 22

n.4

p. $820-836$

out./dez. 2020 


\section{RESUMO}

O artigo apresenta o trabalho de pesquisa realizado pelo autor durante o seu ano sabático (setembro 2018setembro 2019). São recolhidos aqui os antecedentes de pesquisa que levaram ao autor a se perguntar pela vigência da escola e a necessidade de umas ferramentas que permitam pensar sua atualidade. Se mencionam os principais referentes teóricos que foram considerados para construir a categoria de Gramática do Saber Escolar: os estudos etnográficos, a nova história cultural, os estudos sobre cultura escolar, sobre o saber escolar e o saber pedagógico. Finalmente, expõe-se o que se entende por gramática e as regras que foram achadas como chaves para pensar o saber produzido pela escola contemporânea. Se explica cada uma delas: o tempo vivo, os afetos abertos, as funções intersectadas e o excedente como possibilidade. Esses aportes também recolhem a experiência do autor como diretor de um colégio durante quatro anos, de cuja sistematização surgiram as regras que se propõem para dar lugar à categoria Gramática do Saber Escolar.

PALAVRAS-CHAVE: Gramática do saber escolar. Escola. Saber escolar. Cultura escolar.

\section{INTRODUCCIÓN}

En el año 2019 emprendí una investigación, apoyada por la Universidad Pedagógica Nacional, para ahondar en torno a lo que significa el saber escolar. El resultado de este trabajo es lo que quiero sintetizar aquí, advirtiendo que aún es necesario seguir profundizando en ello, dada la complejidad que se despliega en la categoría que surgió: La gramática del saber escolar.

La investigación le da continuidad a una pregunta que me he hecho desde hace tiempo sobre la vigencia de la escuela en la contemporaneidad. Mi primer trabajo mostró cómo se hizo necesaria la escuela (ÁLVAREZ, 1995), en el proceso de institucionalización que cubrió todo el siglo XIX, y luego me pregunté si aún era necesaria (ÁLVAREZ, 2005), con la emergencia de los medios de comunicación como la radio, el cine y la televisión.

Ahora sabemos que la escuela está ahí, a pesar de todas las críticas que se le hacen; a veces cuesta entender cómo ha sobrevivido a las fuertes demandas del mundo de la empresa, del pensamiento crítico, de las teorías de la comunicación, de los nuevos derechos de la infancia y de la pedagogía misma; todas estas demandas y críticas, aunque parten de intereses y de supuestos distintos, coinciden en afirmar que la escuela todavía reproduce formatos propios de un mundo en decadencia, relacionados con sistemas de autoridad, con concepciones de la ciencia, o con valores que ya no le sirven al mundo de la producción económica, a las nuevas ciudadanías ni a los proyectos de emancipación. Con todo, la escuela parece tener vida por largo tiempo. ¿Cómo sucede esto?, ¿por qué? En parte, la respuesta a estas preguntas puede encontrarse si escudriñamos las reglas básicas y los códigos de funcionamiento de ese saber que le permite seguir siendo socialmente pertinente. Es a ello a lo que llamaremos Gramática del Saber Escolar (GSE). 
La pregunta que hacemos ahora entonces es: ¿qué es lo que sabe la escuela?; ¿qué la hace aún pertinente? En este escrito no pretendemos responder la segunda pregunta; tan sólo nos aproximamos a la primera, pero creemos que de allí surgen pistas que pueda llevarnos a responderla.

\section{APROXIMÁNDONOS A LA GSE}

Explorando la pregunta por la gramática del saber que atraviesa a la escuela, nos acercamos a los planteamientos que desde hace años se vienen haciendo en torno a la noción de cultura escolar. Buscamos en los trabajos sobre etnografía escolar (ROCKWELL, 2018; ROCKWELL, 2015) pues allí reconocemos que ha habido una aproximación a la vida íntima de la escuela y su poder descriptivo revela con detalle la riqueza propia de su cotidianidad. Luego recorrimos la literatura de procedencia española en torno a la noción de cultura escolar (VIÑAO, 2002). Esta importante producción intelectual partió de los trabajos de historia de la educación que buscaron ir más allá de la tradicional historia de las ideas pedagógicas, o la historia de las instituciones educativas y de los pedagogos. Bebieron de la historia cultural que venía siendo trabajada desde los nuevos paradigmas incorporados por la historiografía francesa de los Annales y por los escritos de autores como Walter Benjamin (2009). Desde allí se produjo también un interés por la cultura material de la escuela (ESCOLANO, 2007) y surgieron reflexiones sobre la museística escolar, ligadas a trabajos de largo aliento como los de Roger Chartier sobre historia de la escritura (CHARTIER, 1999) o de David Hamilton (1991) preguntándose por la red de elementos educativos como el libro de texto, el currículum, la catequesis, la disciplina y la didáctica que dieron identidad cultural no solo a la escuela, sino a la sociedad moderna.

Ahora bien, ¿cuál es la particularidad de nuestra mirada? El Grupo Historia de la Práctica Pedagógica (GHPP) - del cual soy miembro- ha participado de estos debates apropiando de Michel Foucault (1970) la categoría de práctica, para plantear que más allá de la historia cultural de la educación, conviene mirar la forma por medio de la cual la escuela se convirtió en una institución necesaria para la sociedad y cómo ella hizo parte de una práctica discursiva que dio lugar, a su vez, a un saber como el pedagógico y a unas subjetividades que llamamos hoy maestro y estudiante (ZULUAGA, 1987). En la misma perspectiva habían hecho un trabajo arqueológico sobre la escuela Julia Varela y Fernando Álvarez (1991); haciendo referencia a él, Varela (2003) plantea que en ese entonces se habían analizado los aspectos constituyentes de la escuela moderna y sus modos de operar, entre los que menciona: la aparición de la infancia, su confinamiento en un espacio para educarla y la designación de un sujeto para encargarse de ella, al tiempo que surgía un saber especializado para guiar dicha tarea, la pedagogía (p. 142). 
Desde esta perspectiva no se trabaja con la noción de cultura escolar, aunque compartimos sus mismas preguntas, esto es, participamos de su interés por escudriñar los registros que reconocen esta institución como un acontecimiento cultural, ligada a las referencias propias de las mentalidades o de los códigos lingüísticos que la envuelven. Pero no usamos los recursos de la sociolingüística o la noción de estructura (BERNSTEIN, 1996) para explorar sus particularidades, sino que trabajamos con las categorías metodológicas de práctica y saber.

Los enfoques con los que trabajan los teóricos de la cultura escolar también se han alimentado de la antropología cultural que, desde la perspectiva del interaccionismo simbólico, como lo plantea Geertz (2003), permitirían analizar la estructura de significaciones del mundo de la vida, tal como las personas la asumen en su transcurrir diario. En ese sentido, desde la etnografía se insiste en que la cultura escolar está caracterizada por acciones propias, y el pensamiento de sus actores no estaría determinado por el contexto, pues tendrían un grado de autonomía que la harían singular. Como se ve, se juega allí con un adentro y un afuera y debaten sobre el grado de influencia que uno pueda tener sobre otro. Los trabajos de Elsie Rockwell citados arriba terminaron planteando un debate con los enfoques propios de las pedagogías críticas, de raigambre marxista, que denunciaban a la escuela por considerarla un aparato ideológico del Estado al servicio de la dominación capitalista. Liberar a la escuela de esta lectura reduccionista y determinista fue muy importante.

De todas estas miradas que consideramos próximas a la noción de GSE, nos queda la duda, no sobre el grado de autonomía de la escuela, sino sobre la existencia de un adentro y de una afuera, de unas fronteras y una identidad que terminan por naturalizarla. Aquí no se quiere ver la escuela como una institución en el sentido sociológico, antropológico y menos económico, cuyas fronteras estén en cuestión, sino como un acontecimiento de saber. La noción de saber es útil para pensar la escuela más allá de sus fronteras institucionales. El saber sería el territorio más amplio en el que una formación discursiva se constituye.

\section{LA GRAMÁTICA DEL SABER ESCOLAR}

La pregunta guía de esta búsqueda que ha llevado a la construcción de esta nueva categoría de análisis es la siguiente: ¿cómo logra la escuela seguir vigente a pesar de repetirse hasta la saciedad que su entorno sociocultural ha cambiado? Las críticas provienen de muy diferentes perspectivas. Las de los empresarios no son las mismas que las del Estado, las de las organizaciones sociales son otras, y muy diferentes a las de la familia, los jóvenes o los intelectuales. No nos detendremos en ellas, pero en general en todos esos cuestionamientos, más allá de los intereses que los mueven, hay una constante y es considerar a la escuela 
conservadora, resistente al cambio y reproductora de prácticas arcaicas ajenas a estos tiempos. ¿Por qué sobrevive? Una primera aproximación a la respuesta nos permite concluir que, aun siendo una institución singular, con sus propias dinámicas, no es estática; ninguna cultura, por antigua o tradicional que sea, se conserva idéntica; en su interior operan mecanismos de renovación que la hacen temporal, esto es, cambia con el tiempo. Si esto es así, si las demandas externas tienen algún grado de influencia y la llevan a adecuarse a ellas, y si internamente también tiene forma de no repetirse, entonces aceptamos que ella tiene cómo sobrevivir. Ahora bien, esto si convenimos que posee una cultura que le da identidad y, por lo tanto, unas fronteras, esto es, un interior y un exterior.

Para salir de esta encrucijada volvamos a la noción de saber que el GHPP ha apropiado de Foucault. El saber sería un registro amplio y abierto de posibilidades en el que el lenguaje actúa para hacer decir y ver de cierta manera. Lo decible y lo visible puede dar lugar a una ciencia, pero también a un modo de pensar no formalizado por reglas controladas (epistemológicas). El saber pedagógico para nosotros sería todo un campo de posibilidades que hace decir y ver la educación de cierta manera, en un momento y en un espacio determinado, incluyendo la escuela; diríamos entonces que el saber escolar es parte del saber pedagógico, pero con unas reglas de formación específicas. Dichas reglas de formación no le confieren identidad alguna, ni le delimitan fronteras, simplemente hacen funcionar el saber de cierta manera; el saber escolar habla de la forma como se escolariza el saber pedagógico que rige una formación discursiva determinada. Si decimos que vivimos un tiempo en el que la vida es gobernada por el discurso del autocontrol (FOUCAULT, 1991), podríamos decir que el saber pedagógico hace posible decir y ver la sociedad del aprendizaje (NOGUERA, 2019), pero nos queda por establecer cuáles son las reglas que operan dicha formación discursiva en la escuela. De allí que necesitemos una GSE. No es una cultura propia y en estricto sentido no es tampoco una gramática de la escuela, sino del saber que hace posible decir y ver de cierta manera en la escuela. La noción de saber nos conecta con la formación discursiva en la que habita y nos libera de pensar en su identidad y en sus fronteras. Siendo así, la GSE sería la que hace posible y necesaria aún la escuela.

La escuela es una institución moderna, es decir, su institucionalización es hija de aquel proceso que dio lugar a una formación discursiva que hoy tal vez estaría en trance, no sabemos si de desaparecer, o de afinarse. Quizás por esa razón se han intensificado las críticas a la escuela y por eso resulta pertinente la pregunta por su vigencia. La respuesta a esta pregunta, insistimos, no la exploramos en su condición de institución, en su formalidad burocrática, sino en cuanto acontecimiento de saber. La escuela como acontecimiento que atraviesa una formación discursiva quizás hoy en trance. 
En la investigación en curso hemos identificado cuatro reglas características de la GSE, estas son: 1. El tiempo vivo, 2. Los afectos abiertos, 3. Las funciones intersectadas, 4. El excedente como posibilidad.

\subsection{Tiempo vivo}

Como he planteado en otro trabajo, la escuela es un acontecimiento (ÁLVAREZ, 1995), esto significa que tiene una temporalidad precisa y tiene un devenir del cual dependen las condiciones que la hacen posible y necesaria. Pareciera obvio hablar de la historicidad de la escuela, pero muchos trabajos se refieren a ella como si fuera inherente a la condición humana; se menciona la escuela en las civilizaciones antiguas, en los griegos y romanos de la época clásica, en la edad media o en los pueblos amerindios. La escuela es un acontecimiento más reciente; las condiciones de su emergencia se relacionan con la aparición del Estado Moderno (monarquías absolutas), en la Europa occidental del siglo XVII. En territorios de América, estas condiciones se dieron en la segunda mitad del siglo XVIII (MARTíNEZ, 1986).

Desde entonces la escuela no ha cesado de cambiar. Es cierto que puede dejar de existir; está siendo advertida de su posible desaparición, por lo menos desde los años cincuenta del siglo XX. Por ello el problema de la temporalidad, de su vigencia, se vuelve un asunto neurálgico hoy en día. Su pervivencia no depende de la voluntad de alguien, sólo de las condiciones cambiantes en las que existe. Pero además de la temporalidad de dichas condiciones. Por ahora, hemos encontrado un modo de ver y de decir, llamado aquí tiempo vivo, que le permite operar en dichas condiciones cambiantes.

Se trata de un modo de ser del saber en disputa permanente; hay una batalla constante por su legitimidad, más o menos silenciosa, que le permite acomodarse a ciertos cambios, e incitarlos también. Los ritmos de dicha batalla van cambiando y le van marcando su modo de ser en diferentes momentos. Como efecto de múltiples batallas van cambiando los modos de ser estudiante, de ser maestro, de ser padre de familia, pero también de ser currículo. No es igual ser estudiante o maestros en la escuela lancasteriana que en la escuela activa ni en la escuela de los derechos; no es equivalente ser un padre de familia campesino resistiéndose a enviar sus hijos a estudiar en el siglo XIX, a ser un padre de familia reclamando gratuidad para que todos sus hijos puedan escolarizarse, o el acudiente de la familia extensa o polifuncional buscando cómo mantenerlos matriculados. No es lo mismo hablar de los ramos de instrucción, los planes de estudio, el pensum, el currículo, las áreas obligatorias, las competencias o los derechos básicos de aprendizaje. No son cambios sutiles, son profundos y tienen que ver con el modo de ser del conocimiento que también va cambiando. Este saber, que hace ver y decir de cierta manera, va produciendo unas posiciones de sujeto, unas 
modalidades de objeto y unos tipos de relacionamiento que son descriptibles (FOUCAULT, 1970).

La forma como se van produciendo los cambios en ese modo de ser del saber no obedece a una misma ley que permita predecir su dirección, su permanencia o su duración. Como intervienen tantos factores, como se trata de un saber móvil, decimos que obedece a un tiempo vivo; es vivo porque es cambiante, pero además porque el azar interviene en su devenir. La aleatoriedad de las dinámicas de cambio del saber escolar es su condición. Se puede decir que ésta no es una regla exclusiva del saber escolar, que es propia del saber, en cualquiera de sus manifestaciones, sí, pero dicha aleatoriedad, su modo de devenir, adquiere una modalidad específica que le caracterizan. Describir la cotidianidad escolar de la que dan cuenta los estudiosos de la cultura escolar, no basta para pensar su temporalidad; por eso es tan importante la mirada histórica de larga duración, para poder percibir las mutaciones, los momentos de quiebre en el modo de ser sujetos, en el modo de ser de los objetos que la constituyen, en el modo de establecer las relaciones estratégicas con la política, con la sociedad o con el conocimiento, en fin.

Una cosa es describir las características de la gramática escolar para mostrar cómo tienden a permanecer sus estructuras, sus cánones y sus rituales, a pesar de tantos intentos de reforma que desde las instancias gubernamentales se implementan (TYAK y CUBAN, 2000), y otra es pensar la GSE en su tiempo vivo, que habla de su modo de ser acontecimiento, de su capacidad de mutar, dadas ciertas condiciones descriptibles. Los cambios que se experimentan no están producidos por las normas, ni por los actos conscientes de resistencia o de innovación que algunos actores quieran promover; por supuesto que esto incide, pero dichos cambios terminan siendo el resultado del modo como el saber escolar marca sus ritmos, que van a ser de corta, mediana y larga duración. Entre sus tiempos rutinarios: horas de ingreso y salida, el recreo, horarios de clases, períodos académicos, de vacaciones, de grado a grado, de ciclo a ciclo, de nivel a nivel, entre estos tiempos preestablecidos y los que marcan lenta e imperceptiblemente las grandes transformaciones, hay un juego en el que interviene el azar, pero también ciertas necesidades propias de la sociedad o de la economía.

El espacio escolar, por ejemplo, no ha sido siempre el mismo; una historia de la arquitectura escolar (MALDONADO, 1999) nos permite ver la inmensa diversidad de estructuras, de edificios y de modelos arquitectónicos que han existido. Desde el cuarto o habitación que podía estar en cualquier casa, edificio público, incluso al lado de la cárcel, en el siglo XIX (ÁLVAREZ, 1995), pasando por los espacios campestres con aulas semiabiertas, o los edificios enrejados de varios pisos de las grandes urbes. Pensar el tiempo vivo de la escuela nos permite ver la escuela en su versatilidad espacial, en este caso. También podríamos 
ilustrar la forma como han cambiado drásticamente los recursos educativos, los materiales didácticos y los utensilios; los museos escolares son escenarios maravillosos, donde podemos ver y contrastar las épocas a partir de la materialidad de su existencia (ESCOLANO, 2007). Allí se exhiben, desde los primeros tablones para sentarse los estudiantes, hasta los pupitres más ergonómicos de hoy, desde los Gises de carboncillo y las tabletas de piedra, hasta las tablets de ahora, los tipos de uniformes, los utensilios para educación física o los instrumentos musicales, los libros de texto con muy pocas ilustraciones, hasta los que se diagraman en colores con abundantes ilustraciones; en estos últimos se puede ver también los muy diferentes tipos de relaciones que se establecen con la ciencia y con los saberes populares, con la escritura, la gramática y con el conocimiento mismo.

Para percibir la complejidad que significa pensar la escuela hoy, creemos útil tener en cuenta esta primera regla que interviene en el modo como la escuela deviene, cómo cambia, cómo muta en todas sus formas. Es el tiempo vivo el que primero marca el saber escolar.

\subsection{Afectos abiertos}

El mundo de los afectos está presente en la escuela de una manera especial, teniendo en cuenta la convivencia de personas de tantas edades, con roles distintos y procedencias culturales y sociales diversas. Al igual que el tiempo vivo, lo afectivo hace parte de las dinámicas de cualquier institución social, pero en la escuela se interactúa con ello de cierta manera. Todo lo que aparece en su forma no lingüística, no discursiva (LAZZARATO, 2006), relacionado con los gestos, los tonos del habla, los sentimientos, las emociones, los temperamentos, las personalidades, los miedos, las taras, los traumas, los silencios o los gritos, en fin, el mundo de lo sensible es importante describirlo como una regla que interviene en el saber escolar. Son fuerzas que Lazzarato (2006), siguiendo a Guattari, llama moleculares o preindividuales y pertenecen al orden de lo corporal y lo visible; la manera como se dispone el espacio, su estética, su diseño, sus colores, las distancias, las formas, todo está hablándonos de una variable de lo que sabe la escuela. Son espacialidades múltiples, no son iguales, no hay uniformidad, pero sí mucha expresividad. Esa regla suele ser la menos atendida a la hora de pensar lo que le pasa a la escuela, por lo general se subvalora porque se considera que interfiere en la normalidad, o si se quiere que altera un orden deseable. Cuando hay gritos o violencia, cuando hay altercados, cuando aflora la envidia, los celos o la rabia, se rechazan y se tratan de neutralizar porque harían parte de lo no deseado que retrasa o desvía el orden planificado y los nobles propósitos de la formación de ciudadanos. Tal vez por eso las evaluaciones institucionales, la planificación, los parceladores y los exámenes, son tan necesarios en la escuela; serían como el pliegue, el revés de lo que acontece en el mundo de lo sensible. Para Lazzarato (2006) lo que allí opera sería una disyunción, un efecto de alteridad 
complementaria en el que no hay consenso ni solución posible. Entre el mundo de lo sensible y el de la racionalidad lingüística habría un disenso que, en nuestro caso, sería lo que caracteriza esta segunda regla de la GSE.

Así como se requiere una distancia en el tiempo para pensar el tiempo vivo de la escuela, necesitamos tomar distancia emocional del mundo a-significante para no juzgar negativamente la rica experiencia que, movida por el deseo, hace que la escuela sea un espacio apasionante. Puede molestar, o decepcionar a veces, cuando emocionalmente no le es favorable a quien lo juzga, pero en general es una regla vital para pensar cómo la escuela se ha vuelto tan necesaria en la sociedad. Para los estudiantes significa uno de los motivos fundamentales para permanecer allí; el mundo de los amigos y amigas, de los noviazgos, del despertar sexual, de las intimidades y los secretos que acontecen en y por la escuela, todo ello resulta existencialmente fundamental en la vida de ellos. El ser maestro está marcado también por estas vivencias y quizás sea uno de los distintivos mayores frente a otras profesiones. Esta regla nos muestra también, más allá de los roles preestablecidos (maestroestudiante-padre de familia), cómo el deseo atraviesa los cuerpos indiscriminadamente; una rabieta, los celos, la envidia, la compasión, la solidaridad, la fidelidad o la traición, no distingue entre unos y otros, no tienen edad ni funciones. Nos interroga acerca de lo ininteligible, de lo que siendo vital no podemos asir pues no es fácil explicar racionalmente; pero está allí y habla de la multiplicidad, de la disyunción, de lo múltiple y de la densidad del saber escolar. En esta dirección no cabe el mundo cerrado de la lógica, sino el mundo abierto de los afectos. Por estar abierto sabemos que nunca hay acuerdos entre las partes, siempre que en la escuela se trata de regular (con castigos y sanciones establecidas en el manual de convivencia o el reglamento escolar), se producen reacciones que no cesan; allí los litigios nunca son resueltos, sino que se activan incesantemente. Los ilegalismos son constitutivos de esta regla, sin ellos la escuela no sería lo que es. El margen de autonomía en este tipo de relaciones, marcado por la corporalidad y los gestos, es el que determina su potencial creador, más allá de cualquier sometimiento. Lo que para algunos es opresión y violencia, acá podría pensarse como experiencia formativa, pues dejaría una huella sensible que enseña a moverse mejor en el mundo. Hay mucho más en juego de lo que tradicionalmente se dice. Con esta regla podremos luego entender, más allá de lo que una teoría pueda decir, cuál es el potencial político del saber escolar, y entender por qué insistimos en hablar de saber y no de disciplina o de ciencia, a la hora de pensar la escuela. 


\subsection{Funciones intersectadas}

Desde el siglo XVII, cuando dijimos que se crearon las condiciones para que emergiera la escuela, se le han venido asignando funciones de muy diversa índole, provenientes de los intereses sociales que entran en juego a la hora de querer poseerla para gobernar la población en un sentido o en otro. A la escuela se le ha requerido para resolver un problema relativamente elemental, la atención de las nuevas generaciones para liberar el tiempo de los padres que deben ocuparse del trabajo. Y esto sucede por dos razones: 1) porque se considera que la población debe ser instruida para entender los códigos numéricos y lecto-escritores de la sociedad y, 2) porque el proceso de industrialización y urbanización de la sociedad requería una mano de obra disponible para intensificar la producción de bienes materiales que comenzaban a expandir el mercado a un nivel planetario. Desde entonces, a los pequeños se les requiere cada vez menos en el trabajo y cada vez se alarga más el tiempo y las exigencias de formación para responder a las exigencias del mundo productivo y de la vida civilizada (según los códigos de la Europa occidental de los siglos XVII a XIX). En estas circunstancias aparecen los aparatos de Estado que se encargaron de escolarizar a todos los niños, primero, y luego a las niñas. Si seguimos a Foucault (CASTRO-GÓMEZ, 2010) en la descripción de las formas de gobierno que han regido a Occidente desde el siglo XVII, diríamos que allí la escuela ha cumplido un papel fundamental en el disciplinamiento de la población.

Desde finales del siglo XIX y la primera mitad del siglo XX a la escuela se le comenzó a pedir que les permitiera a los niños aprender de su entorno inmediato, de la naturaleza y en un espacio de libertad donde habría de desplegar sus capacidades innatas para ser conducidas hacia los propósitos de la nueva ciudadanía, emancipada ya del poder soberano de las monarquías. Todas las corrientes conocidas como escuela nueva, pedagogía activa, pedagogías libertarias, y más tarde pedagogía institucional (con influencia del psicoanálisis), constructivismos y educación popular, han contribuido a romper las estructuras rígidas y disciplinarias de la escuela. Como veremos, esta nueva función se interceptará en el siglo XXI con las tendencias propias de la educación sin escuela. Pero fue también en este período (primera mitad del siglo XX), que la escuela se higienizó y jugó un papel fundamental en la tarea de gobernar la vida (función biopolítica, en clave de Foucault). La escuela ayudó a medir a los menores con todo tipo de tamizajes para prevenir enfermedades y para formar hábitos higiénicos necesarios en el proceso de modernización urbana y en la búsqueda de eficiencia productiva, con los nuevos desarrollos tecnológicos de la industria.

Después de la Segunda Guerra Mundial (1945-1980) la llamada Guerra Fría que polarizó el mundo en dos bloques político-económicos, produjo una carrera armamentista, espacial y de productividad que desafió a la escuela a intensificar su capacidad para instruir 
también con eficacia a las masas, ya no solo de niños, sino de jóvenes, sobre todo pensando en alfabetizarlos en los nuevos códigos que los avances tecnológicos, más tele-mediáticos, estaban demandando. Allí la escuela debía ser funcional al llamado Desarrollo y a la sociedad de bienestar que éste prometía (MARTíNEZ, CASTRO y NOGUERA, 1994). Los mecanismos de regulación biopolítica se hicieron más eficaces a través de la llamada tecnología educativa y el diseño instruccional.

Desde los años ochenta del siglo XX, después de la crisis energética que los países petroleros generaron cuando crearon un cartel para imponer los precios de los hidrocarburos, el modo de producción giró buscando extraer la plusvalía, no del tiempo no pagado del trabajo, sino del conocimiento que el trabajador le incorporaba a la mercancía, permitiéndole desplegar su creatividad y capacidad de innovación. Así las industrias llamadas sin chimeneas, las industrias culturales, las empresas prestadoras de servicios, el sistema financiero, el turismo, en general la producción de bienes no materiales o de bienes con alto contenido tecnológico, pasaron a ser las más rentables y el gran capital migró hacia allá dejándole a otras formas de producción (cooperativas, asociaciones, pequeños y medianos productores, maquilas) ocuparse de los bienes materiales. Esto desafía a la escuela para que forme en ella competencias relacionadas con la creatividad, la innovación y la flexibilidad, las características que necesitaría el cognitariado (VIRNO, 2003) que se encargaría de los nuevos procesos productivos. Este tiempo también propendería por la desregulación de la enseñanza para darle mayor protagonismo al autoaprendizaje, y con ello a la posibilidad de prescindir de la escuela misma (homeschooling, escuela virtual o modelos flexibles).

Todas estas funciones se encuentran hoy intersectadas y hacen parte del saber escolar; tal intersección configuraría la tercera regla por cuanto opera impactando la vida de las instituciones educativas. Esto no sucede a través de la normatividad que la rige, o de las políticas educativas que le dan el marco legal en el que funcionan, sino a través de formas más sutiles propias de la volatilidad del saber que legitima ciertas verdades (donde las normas juegan un importante papel, por supuesto).

\subsection{El excedente como posibilidad}

Esta cuarta regla tiene una doble condición, habla de una nueva manera de regular el saber que hace posible la escuela, pero también es una síntesis de las tres anteriores.

La nueva regla es la que se refiere al gesto que Simons y Masschelein (2014) llaman poner sobre la mesa, esto es, la manera como los estudiantes acceden al mundo a partir de sus propias posibilidades y de lo que se encuentran en la escuela en forma de contenidos, de 
currículo, de materias o en general en las experiencias que comparten en la interacción con los maestros, con sus pares y con todas las personas que intervienen en la vida cotidiana de la escuela. Nadie dudaría en aceptar que la escuela está allí para formar a las nuevas generaciones. Lo que ésta cuarta regla quiere plantear, siguiendo los aportes de Simons y Masschelein y de la experiencia empírica, es que tal formación no produce nunca lo que aparece codificado en las normas, en los planes y programas, o en las diversas funciones que, como vimos, se le asignan a la escuela. Lo que sucede en el paso de los niños y jóvenes por la escuela, es una experiencia que ellos procesan según sus posibilidades, y que nunca podrá ser aprehendida por evaluación alguna, por sofisticadas que sean las pruebas. Nadie sabe lo que en realidad aprenden los estudiantes, lo que sí sabemos es que en la vida escolar hay un encuentro con el otro, con lo otro, donde el sujeto es extrañado de sí mismo y de su entorno más inmediato, para entrar en contacto con lo desconocido. Ese mundo otro es lo que llamaremos común. Es común porque está puesto allí de la misma forma para todos, sin distinción; cómo se apropie va a depender de las diferencias que existen entre los estudiantes, pero el mundo está allí a disposición de todos, en igualdad de condiciones. Y está puesto apasionadamente. Hay un empeño por llevar el mundo a la escuela para que ellos accedan a él, un trabajo social y en particular un esfuerzo de los maestros; un sacrificio que significa presencia, maestría y afecto, que compromete la vida misma. De parte de los estudiantes hay también un esfuerzo que pasa por cierta disciplina, cierto rigor, cierta obediencia; de este doble empeño surge la posibilidad de pasar los límites de lo obvio, los límites de lo conocido y de lo repetido, en torno a lo común. Constantemente se está en la escuela en ese borde donde puede aparecer lo inesperado, justamente gracias al movimiento, al cambio, a la disyunción que producen los afectos en su encuentro con la racionalidad, a la intersección de las funciones que se le asignan; esa diversidad que está allí procesada por las reglas de la GSE, se convierten en un excedente que abre la posibilidad de lo otro.

Tal excedente es lo que se asume como lo político de la escuela, pero no en el sentido tradicional, propio de los metarrelatos, de las ideologías, los partidos o el Estado, sino en el sentido que puede actuar un saber como el escolar, con sus reglas de formación, esto es, en el sentido molecular, a través de reglas anónimas de cooperación intersubjetiva que se tejen en el encuentro con la diversidad, con la multiplicidad; esto es lo que hace que lo público del mundo no esté controlado definitivamente, y que sea apropiado según puede cada quien, como sucede en la escuela. Permitir el acceso público al mundo significa que lo que está sobre la mesa en la escuela está abierto, y no se puede manipular porque es impredecible; aunque muchos de sus excedentes sean controlados, sin duda, siempre quedan por fuera modos de ser, modos de ver y modos de decir libres. En ellos está lo político, en lo que se escapa a toda estrategia. 
En la lucha por el control de los excedentes hay un litigio irresoluble; allí opera esto como regla del saber escolar en permanente fricción, de donde proviene lo que se controla, pero también lo que se libera. Lo primero estará cooptado, lo segundo seguirá actuando políticamente dejando abierta la posibilidad de otros mundos. La política así entendida sería el juego permanente de la experimentación con lo desconocido, con la multiplicidad. La proliferación de lo común en la escuela es una regla por cuanto allí, antes que individuos, actúan colectivos, y en dicha actuación se van produciendo comportamientos que a su vez van creando costumbres, no siempre coincidentes con las normas o con las funciones asignadas. Las costumbres de vida en común también se aprenden en la escuela.

Si el saber escolar es testimonio de los mundos posibles que se disputan, ¿cómo crear en medio de tal batalla? La institucionalidad opera como si sólo hubiera un mundo posible, y el saber escolar no puede prescindir de la institución, a riesgo de desaparecer, aun sabiendo que en él se despliega lo múltiple. En esta tensión el conflicto no se dirime dialécticamente, sino asumiéndolo como algo constitutivo, como parte de su gramática. Por lo general se crean bandos que juegan con ello. Una pregunta para pensar la GSE de este presente de la escuela y del debate sobre su sentido actual sería: ¿qué modelos de la eficacia pedagógica controlan nuestras estrategias, esperanzas y juicios sobre la importancia política de la práctica pedagógica?

Siguiendo a Rancière (2019), habría que ir al siglo XVIII para entender de dónde viene la crítica rousseauniana a la pretensión de la escuela ilustrada de transformar el mundo formando a los niños según cierto pensamiento crítico. Rousseau planteaba que pretender que la escuela denunciara las formas de dominación que el oscurantismo ejercía sobre las conciencias, era poner en evidencia que la escuela, supuesto vehículo de la luz, quería actuar como el oscurantismo, moldeando la conciencia. Por eso rechazó la forma escuela y planteó que la educación habría de ser individual, permitiendo que el niño descubriera por sí solo el camino que lo llevaría a aprehender el mundo. Cualquier acción intencionada sobre el niño supondría buscar una eficacia pedagógica que llevaría a la dominación. No sólo se reía de la ingenua pretensión de manipular la conciencia de los niños, sino que denunciaba tal estrategia. Con ella pretendía liberar la educación de toda intención estratégica, dejando a la escuela por fuera de cualquier posibilidad. En esa lógica de negación de la eficacia política de la escuela coincidirían, de un lado quienes hoy cuestionan la flexibilización pedagógica que acaba con los principios de autoridad de los adultos y del conocimiento, y de otro lado quienes consideran que la escuela debe romper sus muros para acercarse a la vida, de manera que las jóvenes generaciones crezcan en libertad. Los primeros porque denuncian a la pedagogía libertaria de manipular ideológicamente la conciencia de los estudiantes, los segundos, 
porque denuncian la forma escuela como un aparato reproductor de la dominación. El primer camino resulta hoy inviable, se trata de una voz que clama en el desierto, sin posibilidad de ser escuchada, de allí su beligerancia (ver textos de los llamados antipedagogos); los segundos no van más allá de la nostalgia, y resulta romántica; la pretendida eficacia política se estrella con lo que aquí llamamos la GSE, y es que ella, más allá de los propósitos estratégicos, se encuentra con que la eficacia política de la escuela no está dada por los fines que se le asignen, sino por su potencia impredecible y silenciosa.

Los jóvenes que egresan de las escuelas que conservan el orden, la disciplina, la enseñanza de contenidos, el rigor y el esfuerzo por encima del diálogo y la democracia, no van a ser disciplinados, ordenados y rigurosos; o en todo caso es impredecible, porque la escuela no tiene el control sobre sus vidas por fuera de sus muros, ni antes, ni después de que salgan. Lo mismo diríamos para quienes sueñan con formar ciudadanos críticos, o consumidores autosuficientes. Lo único que queda de la escuela después de esta batalla por controlar lo que en ella sucede, es su poder de permitirles a los estudiantes estar en ella experimentando la gramática de su saber, sin una finalidad.

Los críticos de la escuela actual sean defensores de sus formas canónicas que supuestamente eran eficaces por garantizar que se formaran personas capaces de transformar el mundo como la modernidad propuso, sean defensores de la educación emancipatoria, como alternativa política al orden establecido, sean defensores de la idea de que se abra a las redes de comunicación telemática, unos y otros están atrapados en la crítica misma. Insisten en que se transforme para que recupere lo que ya no está en el horizonte de posibilidades históricas, o insisten en que se transforme para que se acerque a la vida, que se vuelva un centro interactivo, lúdico y flexible, o se diluya en las múltiples experiencias que le propicia la vida cotidiana, que serían per se educadoras. Estas miradas críticas sobre la escuela no pretenden otra cosa que su dilución en su forma actual, pretenden separar lo que hoy sabe la escuela, de lo que sabe la filosofía moderna, la corriente revolucionaria o la tecnocracia neoliberal; separarla querría decir quitarle su potencia impredecible y silenciosa para integrarla a lo que no es. Estas críticas actúan como fuerzas que pugnan en últimas por su dilución.

Lo que le permitiría a la escuela seguir existiendo es su ausencia de voluntad y propósito. Ella sigue allí porque no hay otro lugar donde niños y jóvenes puedan estar mejor mientras los adultos trabajan. Esto es lo que la hace potente, porque en ella habita un interés común ineludible. Beneficia a todo el mundo. Y los estudiantes allí se encuentran, en ese espacio común. 


\section{FINAL ABIERTO}

La GSE sirve para entender la escuela como acontecimiento y no como institución, ayuda a ver las invenciones que en ella se producen, no como disfunciones, como anormalidades, como problemas, conflictos indeseables o como fracasos; no, más bien los ilegalismos allí se vuelven creación, apertura a otras posibilidades. La sociología o incluso la antropología cultural y todas las perspectivas constructivistas que la abordan, no le dan un lugar a lo imprevisible, que por lo demás abunda en la escuela; por eso sólo pueden ver cómo se produce y se reproduce, pero no ven cómo se multiplica hacia otros mundos posibles, inesperados; ven aquello que se reproduce por imitación, descubren las leyes, las reglas y la gramática de la reproducción, pero no pueden ver esos gestos como experimentación, lo que es tan propio de la pedagogía, sino como desvíos a controlar, para intentar volver a las esencias conocidas.

Acabar con la escuela sería iluso y no se vislumbran las condiciones para que esto sea posible, por ahora. Sólo mentes ingenuas alcanzan a insinuarlo, pero sin fundamentos y sin la inteligencia suficiente para entender lo que está en juego. Ningún organismo, ni los expertos, ni los pedagogos, ni los antipedagogos, mínimamente sensatos, podrían atentar contra las estructuras básicas de la GSE. A veces la virulencia de los argumentos a favor o en contra, muestra la trascendencia de lo que está en juego. La escuela es una institución estratégica para cualquier forma de ejercicio del poder. Eso no quiere decir que no se le puedan incorporar modificaciones, por supuesto que sí, y lo hacen. En todo caso ninguna acción a favor o en contra de las innovaciones pedagógicas, con todos sus matices, provienen de un sujeto o una conciencia o inteligencia que manipule o controle esto. En las dinámicas propias de la GSE se tensionan entre sí tendencias, fuerzas que actúan en una dirección o en otra y hacen que el mapa de relaciones esté abierto a seguir su camino en direcciones impredecibles.

No es entonces una acción de resistencia, como Tyak y Cuban (2000) plantean, lo que hace que la escuela conserve sus tradiciones. La descripción etnográfica o la memoria activa del saber escolar que se expresa en los objetos de los museos y que se reivindican como patrimonio cultural, son acciones que afirman la vigencia de esta gramática. El debate entre pedagogos y antipedagogos presente en las cumbres internacionales, o entre empresarios, en las agencias del estado, en la academia, incluso entre pedagogos y maestros, o entre la opinión pública a través de los medios de comunicación masiva, es expresión de esta encrucijada en la que se encuentra la escuela. El saber que produce a la escuela no es un mundo fácil, está agrietado, está en conflicto, es frágil, vive en medio de muchas tensiones; 
por momentos se viven situaciones absurdas, incluso dramáticas, pero no puede ser de otra manera pues es el riesgo de producirnos juntos, y esto es a lo que no se quiere renunciar. Así, queda abierto el destino de la escuela.

\section{REFERÊNCIAS}

ÁLVAREZ, Alejandro. ... Y la escuela se hizo necesaria. En busca del sentido actual de la escuela. Bogotá: Magisterio, 1995.

ÁLVAREZ, Alejandro. Los medios de comunicación y la sociedad educadora: ¿ya no es necesaria la escuela? Bogotá: Magisterio, 2005.

BENJAMIN, Walter. La dialéctica en suspenso. Fragmentos sobre la historia. Santiago de Chile, Ediciones LOM, 2009.

BERSTEIN, Basil. Pedagogía, control simbólico e identidad. Madrid: Ediciones Morata, 1996.

CASTRO-GÓMEZ, Santiago. Historia de la gubernamentalidad. Razón de Estado, liberalismo y neoliberalismo en Michel Foucault. Bogotá: Siglo del Hombre Editores, 2010.

CHARTIER, Roger. El estatuto de la historia. Entrevista con Roger Chartier, Memoria y Sociedad, v.3, n.6, 1999. p. 5-12.

ESCOLANO, Agustín. La cultura material de la escuela. Berlanga: CENICE, 2007.

FOUCAULT, Michel. La arqueología del Saber. México: Siglo XXI, 1970.

FOUCAULT, Michel. La Gubernamentalidad. En: Espacios de Poder. Madrid: La Piqueta, 1991.

GEERTZ, Clifford. La interpretación de las culturas. Barcelona: Gedisa, 2003.

HAMILTON, David. Orígenes de los términos' "Clase" y "currículum". Revista de Educación, n. 295, p. 187-206, 1991.

LAZZARATO, Maurizio. Políticas del acontecimiento. Buenos Aires: Tinta Limón, 2006.

MALDONADO, Rafael. Historia de la arquitectura escolar en Colombia. Bogotá: Universidad Nacional de Colombia, 1999.

MARTÍNEZ BOOM, Alberto, CASTRO, Jorge Orlando y NOGUERA, Carlos Ernesto. Currículo y Modernización: cuatro décadas de educación en Colombia. Bogotá: Foro Nacional por Colombia. Tercer Milenio, 1994. 
MARTÍNEZ BOOM, Alberto. Escuela, maestro y método en Colombia, 1750-1820. Bogotá: Universidad Pedagógica Nacional, 1986.

NOGUERA, Carlos. Notas sobre el fin de la educación. En: NOGUERA, Carlos y RUBIO, David. Genealogías de la pedagogía. Bogotá: Universidad Pedagógica Nacional, 2019. p.175-196.

RANCIÈRE, J. Disenso. Ensayos sobre estética y política. México: Fondo de Cultura Económica, 2019.

ROCKWELL, Elsie (coordinadora). La escuela cotidiana. México: Fondo de Cultura Económica, 2015.

ROCKWELL, Elsie. Vivir entre escuelas. Relatos y presencias. Buenos Aires: CLACSO, 2018.

SIMONS, Maarten y MASSCHELEIN, Jan. Defensa de la escuela. Una Cuestión Pública. Madrid: Miño y Davila, 2014.

TYACK, David y CUBAN, Larry. En busca de la utopía. Un siglo de reformas de las escuelas públicas. México: Fondo de Cultura Económica, 2000.

VARELA, Julia y ÁLVAREZ, Fernando. Arqueología de la escuela. Madrid: La Piqueta, 1991.

VARELA, Julia. Conocimiento, poder y subjetivación en las instituciones educativas: sobre las potencialidades del método genealógico en el análisis de la educación formal e informal. En: POPKEWITZ, Thomas. (Coord.) Historia cultural y educación: ensayos críticos sobre conocimiento y escolarización. Barcelona-México, Pomares, 2003.

VIÑAO, Antonio. Sistemas Educativos, culturas escolares y reformas: continuidades y cambios. Madrid: Ediciones Morata, 2002.

VIRNO, Paolo. Gramática de la multitud. Madrid: Traficantes de sueños, 2003.

ZULUAGA, Olga Lucía. Pedagogía e historia. Bogotá: Ediciones Foro Nacional por Colombia, 1987.

Revisão gramatical realizada por: Miguel Ángel Espitia Raba.

E-mail: miguelangel 9424@hotmail.com. 